\title{
Pyloric-gland adenoma of the stomach: case report of a rare tumor successfully treated with endoscopic submucosal dissection
}

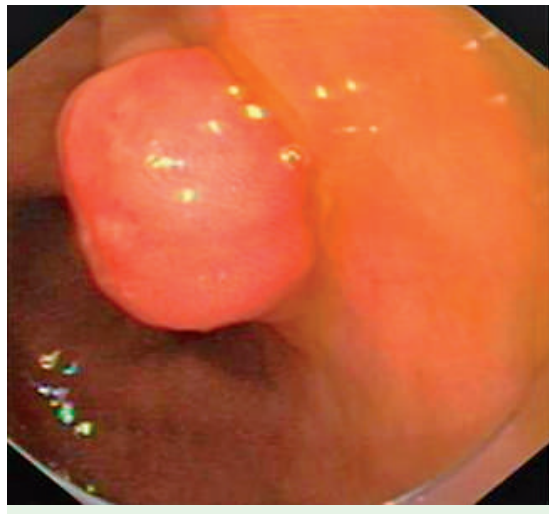

Fig. 1 Endoscopic view of the tumor.

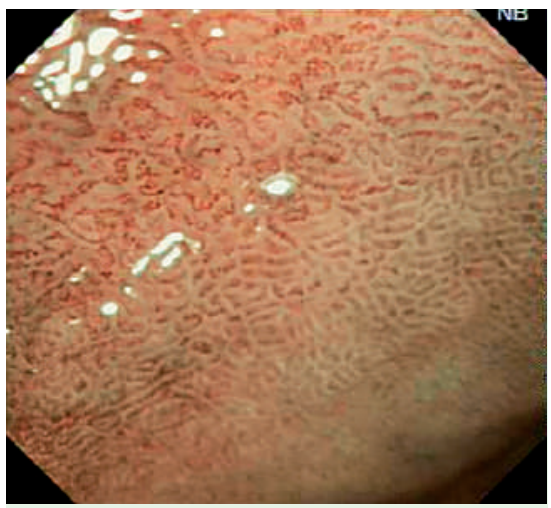

Fig. 2 Tumor as visualized using the narrowband imaging technique.

A 79-year-old woman underwent gastroduodenoscopy because of anemia. A gastric polyp was diagnosed as an incidental finding. The polyp was located in the gastric antrum and measured about $2 \mathrm{~cm}$ ( $\bullet$ Fig. 1). It was of a hard consistency, with bridging folds and a positive lifting sign. The overlying mucosa was intact. Using the narrow-band imaging technique the tumor was seen to have asteroid-shaped mucosal pits and no vascular

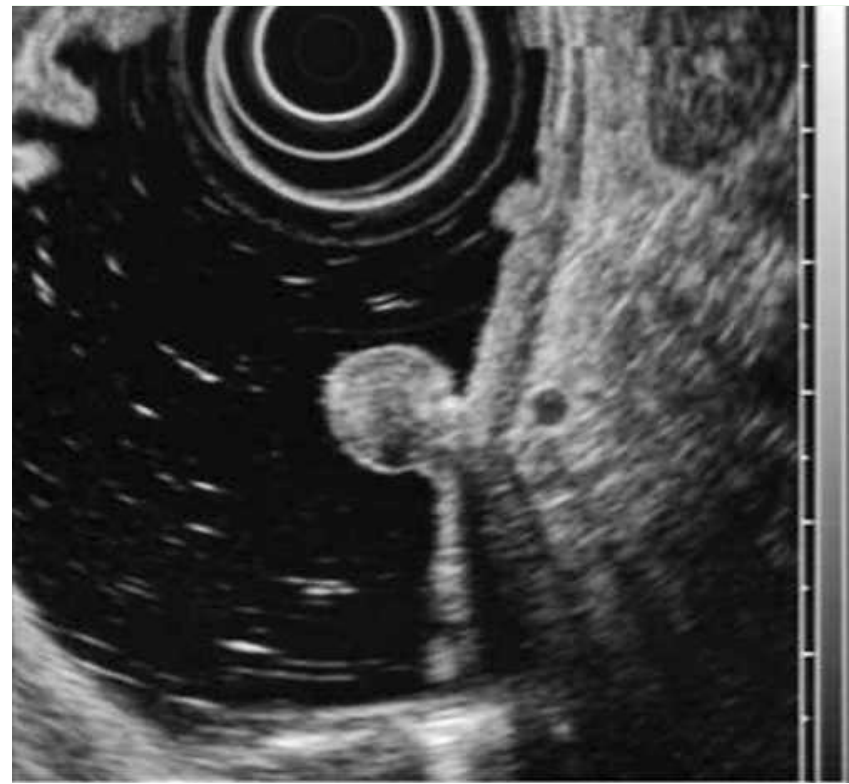

Fig. 3 Endoscopic ultrasonography shows an echogenic tumor within the submucosa.

abnormalities suggestive of malignancy ( $\bullet$ Fig. 2). Biopsies were taken and showed chronic, Helicobacter-pylori-negative gastritis. Endoscopic ultrasonography was performed and showed an echogenic nodule within the submucosa ( Fig.3). For diagnostic and therapeutic purposes we decided to remove the tumor and performed an endoscopic submucosal dissection ( $\bullet$ Fig. 4). The histological examination revealed an adenoma of the pyloric-gland type. There was no evidence of malignant transformation and the resection was complete (๑ Fig. 5).

Pyloric-gland-type adenoma of the stomach is a recently described and rare gastric tumor [1,2]. Apart from case reports, few clinical data and so far only one larger-scale analysis [3] have been published. The name of the tumor reflects its histological resemblance to deep mucoid glands of the gastric mucosa found near the pylorus ('pyloric-type glands'), and immunohistochemically it is strongly positive for mucin 6. Pyloric-gland adenomas are mainly located in the stomach [3], but they can be found anywhere in the entire gastrointestinal tract and have been described in heterotopic gastric mucosa of duodenum and rectum, in the pancreas, gallbladder, and bile duct, the esophagus and even the uterine cervix. They occur more frequently in women and in old age. Their clinical significance is shown by their $30 \%$ rate of malignant transformation. They are considered to be precancerous lesions and endoscopic removal is indicated $[4,5]$. As described in our report, endoscopic submucosal dissection seems to be a highly effective and safe technique.

Endoscopy_UCTN_Code_CCL_1AB_2AD_3AB 


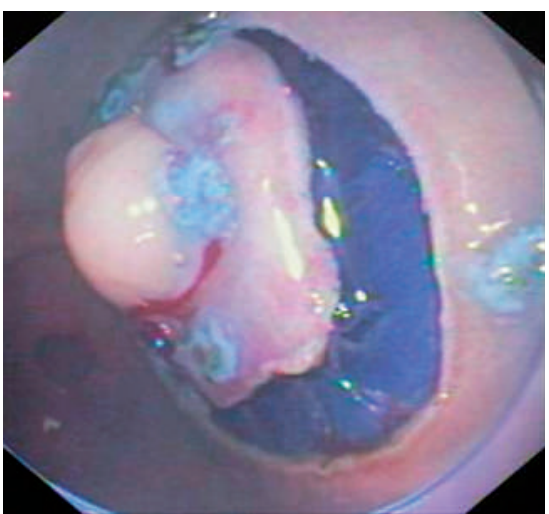

Fig. 4 Endoscopic submucosal dissection of the tumor. After lifting of the tumor by submucosal injection, circumferential incision with submucosal dissection of the tumor is performed.

\section{Golger ${ }^{1}$, A. Probst ${ }^{1}$, T. Wagner ${ }^{2}$, H. Messmann ${ }^{1}$}

1 Department of Medicine III, Klinikum Augsburg, Augsburg, Germany

2 Department of Pathology, Klinikum Augsburg, Augsburg, Germany

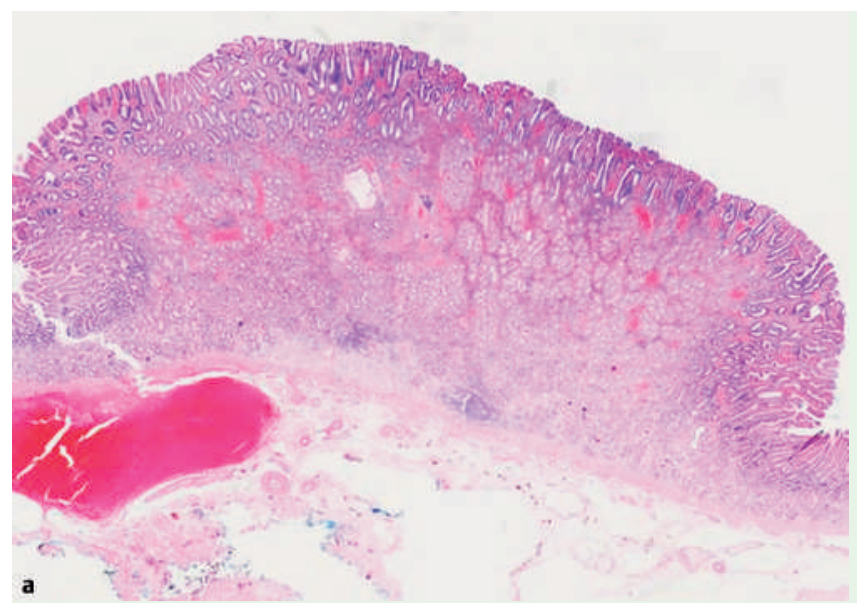

Fig. 5 a,b Histological sections of the tumor show closely packed pyloric-type glands.

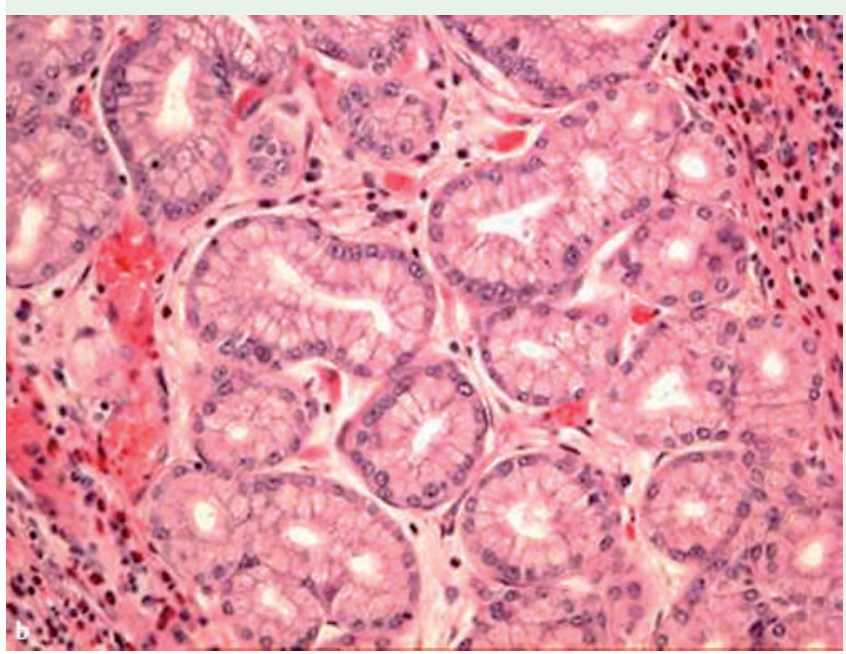

Bibliography

\section{References}

1 Borchard F, Ghanei A, Koldovsky U et al. Gastrale Differenzierung in Adenomen der Magenschleimhaut; immunhistochemische und elektronenmikroskopische Untersuchungen. Verh Dtsch Ges Path 1990; 74: 528

2 Watanabe H, Jass JR, Sobin LH. Histological typing of oesophageal and gastric tumours.Berlin Heidelberg New York Springer; 1990

3 Vieth M, Kushima R, Borchard F et al. Pyloric gland adenoma: a clinico-pathological analysis of 90 cases. Virchows Arch 2003; 442: 317 - 321

4 Oberhuber G, Stolte M. Gastric polyps: an update of their pathology and biological significance. Virchows Arch 2000; 437: $581-590$

5 Schmitz JM, Stolte M. Gastric polyps as precancerous lesions. Gastrointest Endosc Clin North Am 1997; 7: 29-46
DOI $10.1055 / \mathrm{s}-2007-995554$

Endoscopy 2008; 40: E110-E111

(c) Georg Thieme Verlag KG Stuttgart · New York . ISSN 0013-726X

Corresponding author

\section{Golger MD}

Department of Medicine III

Klinikum Augsburg

Augsburg

Germany

danielagolger@gmx.net 